\title{
DARI NALAR LITERALIS-NORMATIF MENUJU NALAR KONTEKSTUALIS-HISTORIS DALAM STUDI ISLAM
}

\author{
A. Halil Thahir*
}

\begin{abstract}
It semslegitimatetosaythat thedassical-conventional mothoddogygies birth to a rigdand theorntricviewof Idam Thisform of mothodbogyis dognaticandisrepletewith a systematic indbctrination, such that would lead one to accet a partiaular view of reigion often bindywhilebdieingthat dhervieus areurong Thispeper offersa hallengetothat ddfashion mothoodogy by deconstruting it, and then construting a newform of mthoddogy. Wetreat the dassical mothoodogy as bingliteral-nomative, and thenewonethat wepropose as bing contextual-historical. Weargue that theformer has goneat of context, because it was invented for its oun time Thelatter in thementimeis citical and considarateto new demands andcontexts Wespeak of thisnewmethoddoyy as haradteisticallymilti-disiplinary in thesense that within its premises varias forms of knowedgearedeemed to havebeen inteconneted and togther constitutean integral web of epistemic constrution Keywords: literal-nomative, contextual-histarical, methodblogy
\end{abstract}

\section{Pendahuluan.}

Metodologi ${ }^{1}$ Studi Islam (MSI), sejak penghujung abad ke-20 menjadi salah satu kajian yang "digandrungi" oleh para pemerhati dan peneliti masalah-masalah ke-Islam-an, baik di Indonesia maupun di belahan dunia lainnya. Namun demikian bukan berarti bahwa Islam pada abad-abad sebelumnya tidak memiliki metodologi dalam mengkaji Islam² ${ }^{2}$. D alam khazanah Islam klasik telah dikenal berbagai disiplin keilmuan yang dapat dikatagorikan sebagai disiplin metodologi (alat, manhaj) dalam menganalisis Islam. Usilital-fiqh dan qawäid al-figh misalnya, sejak abad pertengahan, oleh para ulama dijadikan pisau analisis utama dalam penggalian hukum (istinbatyal-hlikm) Islam, di samping 'ulumal-Qur'an dan 'ilmallughah seperti naby samaf dan belaghah

Kajian keislaman yang semata-mata didasarkan pada metodologi ala "klasikkonvensional" ini melahirkan wajah Islam yang kaku, teosentris dan sarat dengan dogma. Belum lagi kalau kepentingan teologis dan politik para juris juga ikut bermain dalam memformat Islam, maka Islam akan hadir dengan wajah yang menyeramkan, menangnya sendiri. Segala sesuatu akan dilihat dari dua sisi yang saling berlawanan: musimkafir, múminmshrik, hala haram minnaminhum dan kawan-lawan. Kebenaran dianggap hanya dimiliki oleh kelompok yang pertama, sementara yang kedua dinomor duakan, tertutup baginya akses untuk menyatakan sebagai sesuatu yang benar. Karenanya, ia harus dibendung dan dibumi-hanguskan.

*Sekolah Tinggi Agama Islam Negeri (STAIN) Kediri Jawa Timur.

${ }^{1}$ Metodologi berbeda dengan metode. Metode merupakan langkah-langkah praktis dan sistematis yang ada dalam ilmu-ilmu tertentu dan bersifat aplikatif. Sedangkan metodologi tidak lagi sekedar kumpulan cara yang sudah diterima (well reeived) tapi berupa kajian tentang metode. D alam metodologi dibicarakan kajian tentang cara kerja ilmu pengetahuan. Periksa Muhyar Fanani, MetodeStudi Idam A plikas Sosidog Pengtahuan Stbacai Cara Pandang (Yogyakarta: Pustaka Pelajar, 2008), ix.

${ }^{2}$ Ibid.,vii. 
Sementara di sisi lain, modernitas begitu cepatnya menggelayut dalam setiap detak nadi kehidupan. Permasalahan kompleks silih berganti menghantam sendi-sendi kehidupan umat muslim yang notabene masih hanyut dalam mimpi-mimpi indah kejayaan di masa silam, seraya melantunkan al-isamyalurva layula`alayh

Umat Islam tidak akan dapat ke luar dari belenggu keterpurukan ini, kecuali mereka mau merubah cara pandang mereka terhadap agamanya sendiri dan sekaligus terhadap agama orang lain. Tentu merubah sesuatu yang sudah terlanjur "kronis" ini harus dimulai dari sesuatu yang paling mendasar, yaitu metodologi kritis yang betul-betul sesuai dengan kebutuhan yang, dengan sifat "kritis" tersebut diharapkan dapat membongkar (tafkilk) dogma dan ortodoksi dalam tubuh umat Islam.

Di sinilah kehadiran paradigma keilmuan interkoneksitas menjadi sesuatu yang niscaya (dkanui). Paradigma ini menegaskan bahwa bangunan keilmuan dengan segala ragamnya, baik agama, sosial dan humaniora, maupun kealaman tidak dapat berdiri sendiri. Akan tetapi kerjasama, saling tegur sapa, saling membutuhkan, saling koreksi dan saling keterhubungan antar disiplin keilmuan akan lebih dapat membantu kompleksitas persoalan kehidupan dan sekaligus upaya pemecahannya ${ }^{3}$.

\section{Mengawinkan Berbagai Disiplin Ilmu Pengetahuan}

Setidaknya ada sepuluh macam kajian keilmuan yang harus betul-betul diperhatikan oleh para islamolog (islapiyum) dalam memotret Islam dengan paradigma interkoneksitas, yaitu: Filsafat Ilmu; Filsafat Ilmu dalam Pemikiran Islam; Pendekatan dalam Pengkajian Islam; Insider dan Outsider Perspektif Agama dan Studi Islam; Dirasat Islamiyah dan al-Ulum al-Ijtima'iyah; Fiqh al-Ta'vill wa al-Tafsip (Hermeneutik); Gender mainstreaming (Fiqh al-Nisa'>alMúaini); Intemational Human Right \& Islamic Law Trends in Islamic Thargh Today, dan Philosqphy \& Methoddogy in Isamic Law'.

Di bidang Filsafat Ilmu, pemikiran Charles S. Peirce ${ }^{5}$ adalah satu hal yang sangat mendasar bagi siapa saja yang berminat mengkaji Islam. Bermula dari kritiknya terhadap tiga filosof Eropa, yaitu D escartes, John Locke, dan D arwin, Peirce menggagas teori baru yang sangat terkenal, yakni the new logic (cara berfikir baru) dan the logic of inquiry (logika penelitian). Bagi Peirce, logictidak statis, tetapi bersifat dinamis seiring dengan perkembangan ilmu pengetahuan itu sendiri, sehingga apa yang tampak sebagai fenomena dibaca dan dicerna dengan pembacaan yang kritis-produktif (al-qira'ah al-naqdiyah al-mitijah), bukan malah sebaliknya; membaca apa adanya dan "takluk" terhadap cara pembacaan model warisan para pendahulunya. Pembacaan model terakhir ini, tidak akan pernah menghasilkan sesuatu yang bermakna bagi ilmu pengetahuan dan umat, melainkan taqlid dan mengulang-ulang apa yang menjadi mainstrem (al-qira'gh al-taqiidyoh al-mitakamirah).

Peirce mengajukan lima konstruksi pemikiran: Petama, bdie, yaitu berupa tatanan sosial yang dipegang sementara dan moral; Kedua, habit of mind tradisi yang turun temurun dan menggumpal; Ketiga, daubt (shak, keragu-raguan) akan apa yang selama ini dianggap

\footnotetext{
${ }^{3}$ Amin Abdullah, IsamicStudiesdi PergunanTingg் (Yogyakarta: Pustaka Pelajar, 2006), viii.

${ }^{4}$ Tema-tema Seminar Kelas Mata Kuliah Metode Studi Islam, Program D oktor IAIN Sunn Ampel Surabaya, Semester G asal T.A 2009/ 2010, Kelas K husus. D osen Pengampu: Prof. D R. M. Amin Abdullah.

${ }^{5}$ Milton K. Munitz, ContempararyAnalyticPhilosqphy(London: Collier Macmillan Publishers, 1981).
} 
mapan. Keraguan itu muncul karena adanya benturan antara turath(tradisi) dengan al-hadathah (modernitas). Untuk memperoleh keyakinan, menurut Peirce, seorang peneliti dapat menggunakan empat metode: tenasitas, otoritas, apriori, dan investigasi ${ }^{6}$.

Keempat, Inquiry (penelitian). Namun perlu ditegaskan, bahwa yang dicari adalah mæaning (nilai), bukan truth (kebenaran). Keima; the logic of theory. Pada tahap yang terakhir ini, Peirce menegaskan bahwa kebenaran teks, - baik teks alam, teks manusia dan teks agamaadalah sebagian kebenaran (truth t kecil) yang tertutup dari kebenaran besar (Tnuth $\mathrm{T}$ besar). D engan demikian, kebenaran yang dihasilkan oleh ekspresi linguistik bersifat relatif (nisa), karena masih banyak kebenaran-kebanaran lainnya yang sama-sama berpredikat " $\mathrm{t}$ " kecil dan masing-masing mengklaim sebagai turunan yang "absah" dari kebenaran dengan predikat "T" besar. D ari sini, kemudian Peirce menawarkan perlunya Commonity of Reerch sehingga masing-masing dari kebenran "t" kecil itu terbuka untuk diapresiasi dan dikritik (qakil li alniqas) $)^{7}$.

Berbeda dengan penelitian alam (natural sience) yang bersifat positivistik, penelitian agama bersifat humanistik dan mempunyai dua dimensi: Beief (imari)yang bercorak teologissubyektif; dan Histary (tarilkh) yang bercorak deskriptif-obyektif. Kalau dalam penelitian alam, bangunan relasi antara peneliti dan obyek penelitian adalah $S-0$, maka dalam penelitian agama yang terjadi adalah relasi S - S.

Namun demikian, tidak dapat dielakkan dalam penelitian agama rentan dengan ketegangan antara pihak insiderdan atsider. Agama sebagai obyek kajian ilmiah meniscayakan adanya sikap lapang dada untuk diperlakukan menurut "selera" peneliti untuk ditelanjangi, sehingga sekujur tubuh agama tampak dengan jelas, mana bagian-bagian yang murni wahyu dan bagian-bagian hasil konstruk sejarah 9 .

Perlu juga ditegaskan di sini, penelitian agama tidak boleh didorong oleh anggapananggapan yang miring (prejudice). Rasa simpati bahkan empati seorang peneliti atas agama yang diteliti sangat dibutuhkan agar menghasilkan kesimpulan yang valid. Persyaratan simpati dan empati juga diperlukan ketika seseorang akan mengkaji budaya dan kondisi sosial masyarakat beragama. Karena logika positivistik-nomotetik yang memokuskan diri mencari hukum-hukum umum dan keteraturan (klaren) tidak bisa menggali wilayah budaya dan sosial, sebaliknya perlu mengedepankan logika ideografis yang berusaha memahami (vetehen) gejala-gejala yang bersifat spesifik ${ }^{10}$. D engan logika ideografis, seseorang dapat menguak

\footnotetext{
${ }^{6}$ Ibid.

${ }^{7}$ Ibid. Berbagai bentuk sikap saling menyalahkan antar umatberagama, bahkan di internal agama itu sendiri yang tidak jarang melahirkan slogan kafir, murtad, sempalan, sesat, menyimpang dan terma-terma lainnya adalah karena hilangnya kesadaran bahwa sesutau yang dinggapnya benar hanya merupakan satu pantulan "kebenaran" makna teks dari sekian ribu pantulan "kebenaran" makna teks. Ironisnya, atas nama Tuhan, yang sejatinya masih dalam konteks kebenaran "kecil" itu terjadi pertumpahan darah beribu-beribu manusia.

${ }^{8}$ D ua model pendekatan terhadap Islam (insiderdan autside) tersebut berangkat dari asumsi dan titik tolak yang berbeda. Kalangan inidermemandang Islam berangkat dari keyakinan bahwa Islam adalah agama wahyu, kebenarannya bersifat mutlak, universal dan adaptif dengan tantangan zaman (salihlli kull zaman wa makan). Buahnya adalah, kesimpulan-kesimpulan penelitiaanya dikemas sedemikian rupa agar tidak bertentangan denga nilai dasar Islam, yang bisa jadi bertolak belakang dengan fakta di lapangan. Sementara atsidermendekati Islam sebagai fenomena yang menyejarah, yakni agama yang dipahami dan dipraktikkan oleh manusia sebagai makhluq sejarah.

${ }_{9}^{9}$ Rumadi, "Kritik Wacana Agama sebagai G erakan Pemikiran Islam Kontemporer" dalam ed. Adnan Mahmud, et.al., PenikiranIsamKontemparerdi Indonesia(Yogyakarta: Pustaka Pelajar, 2005), 6.

${ }^{10}$ Heru Nugroho, MenumbuhkanIdeideKritis(Yogyakarta: Pustaka Pelajar, 2003), 8.
} 
makna (sinnestehen), bukan sekadar menemukan kausalitas niscaya ${ }^{11}$.

Upaya menetralisir -untuk tidak mengatakan menghilangkan- ketegangan antara dua kutub tersebut, kehadiran disiplin fenomenologi agama sangatlah penting. Walaupun ilmu itu sendiri menegaskan bahwa tidak ada agama yang sama. Atau dengan kata lain, masingmasing agama berbeda dengan yang lainnya. Yang mampu ditelisik fenomenologi agama hanya dari aspek pola, karena di titik inilah berbagai agama dapat dipertemukan. Pola-pola agama dimaksud adalah: doktrin, ritual, teks, leadeship history, morality dan art ${ }^{12}$.

Senada dengan A. James L. Cox, Hegel menegaskan, bahwa seluruh fnomena-termasuk fenomena agama- dalam berbagai keragamannya, bagaimanapun juga didasarkan pada satu esensi atau kesatuan dasar (gist atau spirit). Penekanan terhadap hubungan antara esensi dan manifestasi ini, menjadi suatu dasar untuk memahami bagaimana agama dalam keragamannya pada dasarnya mesti dipahami sebagai entitas yang berbeda. Berdasar penunjukan pada satu realitas transenden yang tidak terpisah tetapi dapat dilihat dalam dunia, juga memberi kepercayaan akan pentingnya agama sebagai suatu kajian karena kontribusi yang akan diberikan pada pengetahuan "ilmiah" ${ }^{13}$.

D engan uraian dan penjelasan ini, maka apa yang dikatakan oleh sementara kalangan adanya pendangkalan aqidah adalah tidak berdasar, karena masing-masing agama mempunyai daya tarik dan kekuatan aqidahnya sendiri-sendiri. D engan model dan pendekatan seperti ini, umat beragama diberi masukan yang cukup berharga bagaimana menghadapi kolega umat beragama lain, dan begitu pula sebaliknya, yang sama-sama mempunyai keyakinan yang kuat akan kebenaran agama mereka sendiri-sendiri tetapi tetap memberi ruang untuk dialog bahkan hak hidup bersama dalam kehidupan yang harmonis (al-táayus/al-silm).

Seorang peneliti agama juga harus epodhe ${ }^{4}$ (mengurung unsur-unsur subyektifitas, baik berupa kepentingan pribadi, kelompok, keturunan dan lainnya). Langkah ini dapat dilakukan apabila peneliti telah menyiapkan kerangka teori dengan matang. Tanpa itu, sulit dan bahkan mustahil akan terhindar dari jebakan subyektifitas.

Sikap epoche dalam penelitian agama mengandaikan adanya sikap kritis (naqd) yang terarah terhadap bangunan keilmuan yang dianggap telah mapan. Dalam kerangka sikap kritis yang terarah ini, kiranya apa yang ditawarkan Abid al-Jabiri tentang pendekatan epistimologi ${ }^{15}$ : bayariss, 'infari ${ }^{1 / 3}$ dan burhari ${ }^{18}$ dalam pengembangan pemikiran Islam kontemporer menemukan urgensinya Karena epistimologi keilmuan yang berkembang di Barat seperti Rasionalisme, Empirisme dan Pragmatisme saja, tidak akan memadahi untuk

\footnotetext{
${ }^{11}$ F. Budi Hardiman, "Positivisme dan Hermeneutik: Suatu Usaha untuk "Subjek", dalam Basis X L-3 (Maret 1991), 92; F. Budi Hardiman, Kritik Idedog: MeningkapKepertinganPengtahuan Besama Jurgen Habemas(Yogyakarta: Buku Baik, 2004), 183; K. Bertens, Filsafat BaratAbadXX: InggrisJemm(Jkarta: G ramedia, 1983), 90.

${ }^{12}$ A.James L. Cox, A Guideto thePhenomendogy of Rdegion: Key Figures Formative Influnces and Subsequent Debates (New york: The O pen University, 2006), 209-247.

${ }^{13}$ Clive Erricker "Pendekatan Fenomenologis" dalam Peter Conolly (ed), Ankka Pendkkatan Studi Agama, terj. Imam Khoiri (Yogyakarta: PT. LKiS Printing Cemerlang, 2009), 110.

${ }^{14}$ Epodheadalah metode meletakkan subyektif peneliti ke dalam kurung untuk menunjukkan karakter ide dan perasaan orang beriman. Periksa, Jamali Sahrodi, Metoddog Studi Isam Mendusuni Jgak HisarisKajian Isamala sarjama Orientalis(Bandung: Pustaka Setia, 2008), 146.

${ }^{15}$ Pemikiran Abid al-Jabiri tentang tiga epistemilogi tersebut dapat dibaca pada Mohammad Abid al-Jabiri>Takima al-Aql al-Arabi(Beirut: al-Markaz al-T haqafi sl-'Arabi>1991. Juga buku berikutnya, Bunjatal-Aqd al-'Arabi-Dirasah

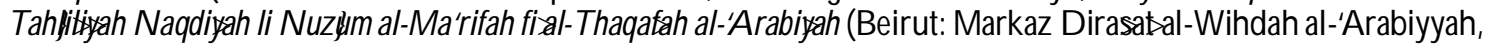


dijadikan kerangka teori dan analisis pasang-surut dan perkembangan Isamic Studies ${ }^{9}$.

Berbeda dengan Abid al-Jabiri, yang melihat Arab-Islam dengan tiga pendekatan epistimologi di atas, Charles J. A dams mengklasifikasikan Studi Islam dalam dua katagori ${ }^{20}$ : Petama, pendekatan normatif atau keagamaan (Nomativeor Reigias Approad). Pendekatan model ini oleh Charles J. Adam diklasifikasikan lagi menjadi tiga pendekatan: missionaries tradisional, apdogatic muslim dan pendekatan irenic ${ }^{1}$. Keetua, pendekatan D eskriptif terbagi ke dalam tiga pendekatan pula, yaitu pendekatan filologi dan sejarah; pendekatan ilmu sosial; dan pendekatan fenomenologi. Metodologi yang ditawarkan C.J. A dams tersebut di atas sangat berarti dalam penelitian agama baik dalam konteks sosio-historis maupun normatif-teologis.

\section{Hermeneutika sebagai Solusi dari Jeratan Dogma dan Ortodoksi}

Dalam tradisi keilmuan Islam klasik, ada dua cara dalam memahami al-Q ur'an, yaitu tafsiredan táwil Tafsiredipahami sebagai cara untuk mengurai bahasa, konteks dan pesan-pesan moral yang terkandung dalam teks atau nasjkitab suci. D engan demikian, teks berposisi sebagai "Subyek". Sedangkan ta'wil>adalah cara untuk memahami teks dengan menjadikan teks dan/ atau lebih tepat disebut pemahaman, pemaknaan dan interpretasi terhadap teks sebagai "obyek" kajian $^{22}$. Hanya saja istilah táwilddalam tradisi 'ulumal-Quran klasik itu, tidak lain dan tidak bukan adalah al-táwil al-batisi yang agaknya equivalent dengan al-tafsis al-ishan³.

Berbeda dengan táwil "konvensional" di atas, kehadiran al-táwilbal-'ilmiłalam rangka menelisik pemahaman orang-perorang, kelompok, mazhab, aliran, organisasi, kultur adalah suatu hal yang niscaya. Al-ta'wilbal-ilmitidak hanya menjadikan teks sebagai obyek kajian, tetapi dilengkapi dengan pendekatan hermeneutis ${ }^{24}$ (al-qira'ahal-munijah) terhadap khazanah

1990, cetakan ke 3. K husus untuk struktur dasar dan pola pikir Mutakallimun (pemikiran Kalamiæah) dapat ditelaah lebih lanjut Josef van Ess, "The Logical Structure of Islamic Theology", dalam Issa J. Boullata (Ed.), An Anthdogy of IdamicStudies, Montreal, MoGill (Indonesia IAIN D evelopment Project, 1992).

${ }^{16}$ Epistemologi Bayari didefinisikan sebagai metode penalaran yang mengacu pada otoritas teks baik secara langsung maupun tidak langsung melalui inferensi (istidal).Periksa, al-Jabiri>Takwin 19.

${ }^{17}$ Dalam menerjemahkan kata 'irfan, kita berhadapan dengan dua padanan yang serupa tapi tak sama. Yang pertama adalah "G nose/ gnosis" yang berarti "pengetahuan intuitif tentang hakikat spiritual yang diperoleh tanpa proses belajar". Sedangkan yang kedua adalah "Gnostik" yang dikhususkan kepada pengetahuan tentang Allah yang dinisbahkan kepada "G nostiksisme"; sebuah aliran kebatinan yang muncul di abad ke 2 M. Kelihatannya pengertian yang kedualah yang dikehendaki oleh al-Jabiri>ibid

${ }^{18}$ Sebagai akitifitas kognitif, demonstrasi adalah inferensi rasional yaitu penggalian premis-premis yang menghasilkan konklusi yang bernilai. Sebagai lapangan kognitif, demonstrasi ini adalah dunia pengetahuan filsafat dan sains yang diderivasikan dari gerakan transliterasi buku asing, khususnya karya Aristoteles ke dalam bahasa Arab. Karena penerjemahan buku-buku itu dilatari oleh kehendak politik untuk mendukung A kal Retoris melawan serbuan tren Akal G nostis, maka tidak heran kalau dalam praktiknya latar belakang ini mempunyai pengaruh yang dominan. D an terjadilah hubungan yang sangat erat antara keduanva dalam dataran metodologi (tata bahasa Arab/ logika) dan juga dalam dataran pemikiran (teologi/ filsafat).

${ }^{19} \mathrm{Amin}$ Abdullah, Isamic Studies 201.

${ }^{20}$ Periksa Charles J. Adams, "Islamic Religious Tradition", dalam Leonard Binder (Ed.) TheStudyMidleEast: Reerchand ScholarshipinHumanitiesandTheSocial Säence(Canada: John Wiley Sons, Inc, 1976), 20.

${ }^{21}$ Ibid.

${ }^{22}$ Amin, IsamicStudies, 184.

${ }^{23}$ Ibid., 185.

${ }^{24}$ Kata Hermeneutik berasal dari bahasa Yunani hemeneuenyang berarti "menafsirkan". Konon, istilah hermeneutika ini punya kaitan khusus dengan sosok yang bernama Hermes (dan yang menduga dia adalah sosok Nabi Idris, Jibril), utusan dari komunitas D ewa O limpus yang bisa berjalan secepat kilat (itu baru cara berjalannya, tidak bisa dibayangkan kalau ia sedang lari). Sebagai perantara, tentu saja Hermes harus bisa menguasai bahasa para dewa, 
intelektual Islam baik klasik, modern maupun kontemporer25.

Abdullah Saed dan Khaled M.Aboe El Fadl adalah dua tokoh yang getol menyuarakan pentingnya hermeneutika dalam memahami teks keagamaan. Berdasarkan pelacakan Abdullah Saed, pendekatan dalam menafsirkan al-Q ur'an dapat dikelompokkan menjadi tiga: tdkstualis, semi tdkstuali dan kontkssualis ${ }^{2}$. Pendekatan model pertama dan kedua ini memperlakukan tekstual al-Q ur'an sebagai acuan dalam memahami pesan yang terkandung di dalam teks, tanpa mempertimbangkan konteks sejarah sosial di mana teks tersebut "diungkapkan". Akibatnya, sering kali terjadi kesenjangan antara tuntutan literal teks dengan dunia empirik, di mana pesan teks itu harus diterapkan. Keadaan ini akan lebih tragis lagi ketika kepentingan ideologis dan politik ikut andil dalam proses penafsiran. Hal yang demikian ini, menurut Khaled M. Aboe Fadl, menjadikan fiqih yang semestinya bersifat "otoritatif" menjadi fiqih "otoriter atas nama Tuhan ${ }^{27 "}$ Lahirnya kelompok muslim puritan-fundamentalis, menurut Khaled M. Abou El Fadl, juga dipicu oleh pemaknaan teks keagamaan bercorak literalistekstualis ${ }^{28}$. Sebaliknya, penafsiran yang "rela" membuka diri untuk melakukan kontekstualisasi terhadap teks akan menghadirkan Islam rahlrah li al-‘alamin dan słalih li kull zaman wa makan dalam segala aspek kehidupan. Sehingga kesan bahwa Islam sarat dengan ajaran bias gender, ${ }^{29}$ tidak relevan dengan kemaslahatan ${ }^{30}$ era kontemporer akan dapat dijawab dengan kepala dingin dan rasional.

Dalam lingkup yang lebih luas, Muhammad Arkoun, berangkat dari kegelisahannya terhadap keberagamaan umat Islam yang cenderung ortodoks, ${ }^{31}$ dogmatis ${ }^{32}$ dan juga terhadap

memahami dan menafsirkan apa yang ada di benak para zat yang kekal itu, sekaligus mampu menerjemahkan serta mengartikulasikan maksud mereka pada makhluq hidup yang ada di dunia fana. D alam pengertiannya yang paling sederhana, hermeneutika bisa didefinisikan sebagai "sebuah teori, metodologi dan praksis penafsiran, yang digerakkan ke arah penangkapan makna dari sebuah teks, atau sebuah analogi-teks, yang secara temporal atau secara kultural berjarak jauh, atau dikaburkan oleh ideologi dan kesadaran palsu" Periksa Maulidin, "Sketsa Hermeneutika" dalam Gebang Jurnal Studi Agama danDemkras No.14 Vol.V (Surabaya: Lembaga Studi Agama dan D emokrasi, 2003), 6. D alam perspektif hemeneutik, paling tidak ada tiga unsur variabel yang harus terpenuhi, yaitu unsur author(pengarang), unsur teks dan unsur reader(pembaca). Dalam Islam, variabel teks adalah nas\$s shar' $i$,variabel authoradalah Allah dan variabel readeradalah umat Islam sendiri. Ketiga unsur variabel tersebut harus diletakkan secara berimbang, karena pengabaian peran salah satu unsur lainnya akan mengantarkan kepada interpreativedespotism(kesewenang-wenangan penafsiran) yang pada akhirnya akan melahirkan authoritarianism, yakni tindakan menutup rapat-rapat atau membatasi keinginan Tuhan (the will of the Divine) atau keinginan terdalam teks dalam suatu batasan ketentuan tertentu, dan menyajikan ketentuan-ketentuan tersebut sebagai sesuatu hal yang final dan tidak dapat diganggu gugat. Periksa Amin Abdullah, "Mendengarkan "Kebenaran" Hermeneutika" dalam Fahruddin Faiz, HemmeatikaAl-Qur’an(Yogyakarta: eLSAQ Press, 2005), xviii-xx.

25. A min, Idamic Studies 185.

${ }^{26}$ Abdullah Saed, Interpreingal-Qur'arx Towardsa ContemporaryApproad(New York: Routledge, 2006).

${ }^{27}$ Khaled M. A boe Fadl, A tasNamaTuhan: dari Fikih OtariterkeFikih Otoritatif (Tp: Serambi, 2004).

${ }^{28}$ Penjelasan mendalam tentang akar munculnya ekstrimisme dalam Islam silahkan baca juga Stepen Sulaiman Schwartz, "D ua Wajah Islam, Moderatisme vs. Fundamentalisme," dalam Wacana Gldbal (Jakarta: The Wahid institute, 2007).

${ }^{29}$ Untuk mendapatkan ulasan tentang gender, silahkan baca Nasr Hamid Abu Zaid, Dawa'ir al-Khauf: Qira'ghfi> Khitabal-Mar'aah(Beirut: al-Markaz al-T haqafi al-'Arabi>2000).

${ }^{30}$ Seluruh ajaran Islam ditujukan untuk mewujudkn kemaslahatan yang sebanyak-banyaknya bagi umat dan sekaligus menolak datangnya mafsadahbagi mereka. Konsep maskahthini oleh ulama telah diformulasikan dalam

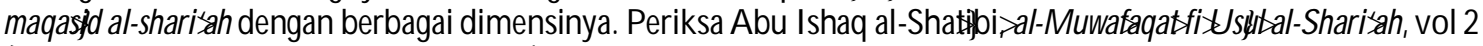
( Beirut: D azal-Kutub al-'Tlmiæah, 1971), 7.

${ }^{31}$ Meskipun kata "ortodoks" tidak dikenal dalam Islam dan tidak mempunyai padanan yang pas dalam bahasa Arab, secara konseptual ide tentang ortodoksi tidak sulit ditemui dalam agama ini. Hal tersebut disebabkan oleh kenyataan bahwa meskipun diungkapkan dalam istilah yang berbeda-beda, konsep ortodoksi dapat ditemui dalam semua tradisi keagamaan yang utama, termasuk Islam. Periksa Abdurahman Mas'ud, "Sunnisme and 
kajian-kajian keislaman yng bersifat logosentris, dia mengajukan gagasan tentang pentingnya memikirkan kembali Islam (RehinkingIsam) yang ada atau berkembang selama ini dan juga pentingnya melakukan kritik terhadap nalar Islam yang telah mengendap di bawah akal sadar umat Islam. Menurut Arkoun, setiap akal mempunyai sejarahnya sendiri yang pasti berbeda dengan akal-akal yang lain.

Kegelisahn Arkoun juga merambah pada persoalan kajian-kajian al-Q ur'an. D alam hal ini, dia banyak melakukan kajian terhadap kitab-kitab tafsir klasik dan juga terhadap para pengkaji al-Q ur'an dari kalangan islamis-orientalis. D ari kajiannya itu, Arkoun melihat bahwa karya-karya tafsir ulama klasik kebanyakan bersifat mitologis, a histars dan ideologis; dalam arti banyak ulama klasik yang mengkaji dan menafsirkan al-Q ur'an sesuai dengan ideologi atau kepentingan politik kelompok tertentu. Padahal tafsir semacam ini, menurut Arkoun, hanya akan menguntungkan para pemimpin atau kelompok-kelompok tertentu saja. Hal ini tentu saja sudah melenceng dari tujuan awal diturunkannya al-Q ur'a ${ }^{33}$

Berangkat dari kesadaran Arkoun akan ruwetnya "nalar Islam," maka dia menawarkan metode historisisme dalam bentuk "kritik nalar Islam" (tanikhiyyat al-'aql al-isami). Teksteks klasik didekonstruksi menuju rekonstruksi ${ }^{34}$. Arkoun melakukan rekonstruksi atau membangun kembali wacana pemikiran agar bisa diperoleh kesadaran atas berbagai penyelewengan, keterbatasan dan pembekuan wacana. Upaya dekonstruksi-rekonstruksi ini bertujuan antara lain untuk menghindari adanya sikap superioritas atau klaim serba paling "pusat", "asli" dan paling "benar" dalam suatu diskursus. Selain itu, upaya ini juga bertujuan untuk menghindari segala sesuatu yang bersifat mitis, ideologis, dan mitologis sehingga suatu diskursus bisa dipulihkan dan ditempatkan kembali secara benar.

Kompleksitas permasalahan Islam kontemporer meniscayakan adanya pembacaan kritis, tidak hanya berkutat dalam ranah "nalar Islam" -seperti yang ditawarkan Arkoun-, tetapi juga harus dilihat dari aspek-aspek lain yang lebih "membumi" dengan kebutuhan umat manusia modern. D alam kerangka ini, gagasan Jasser Auda tentang macasid al-shan'łh dengan pendekatan sistem (a systens approah) dapat dijadikan pisau analisis dalam mengkaji permasalahan Islam ${ }^{35}$. Menurut Jasser Auda, terdapat enam ciri sistem yang, antara satu dengan yang lain saling berkaitan dalam menganalisis hukum Islam kontemporer ${ }^{36}$. Enam ciri sistem tersebut adalah ${ }^{37}$ : pemikiran dasar sistem hukum Islam (cogitivenature of thesstem

'O rthodox' in Eyes of Modern Scholars." Al-Jamiah: Jaumal of Isamic Studies no. 61 (1998), 108. Sheila Mc D onough, "O rthodoxy and Heterodoxy. D alam, Engdopedia of Reigion, vol. 11, 124.

${ }^{32}$ Menurut Arkoun, setiap agama memiliki keyakinan-keyakinan dan non keyakinan-non keyakinan yang telah dilalui sebagai kebenaran-kebenaran yang tidak tersentuh dan tidak dapat diperdebatkan, yaitu, ada dogmadogma yang menghindari setiap pertanyaan kritis oleh kekuatan nalar. Dalam Islam, kata Arkoun, dogma-dogma ditentukan oleh al-Qur'an kemudian dikembangkan dan didakwahkan oleh otoritas-otoritas "ortodoks" pada setiap waktu di mana dipandang perlu membantah pendapat-pendapat yang dianggap heterodoks. Periksa, Muhammed Arkoun, RehinkingIdam terj. Yidian W. Asmin \& Lathiful K huluq (Yogyakarta: Pustaka Pelajar, 1996), 105.

${ }^{33}$ Muhammad Arkoun, al-Fikral-Usłliza Isthalatal-Ta'silłterj. Hashim Salih (Beirut: D as al-Saøi>1999), 17.

${ }^{34}$ Luthfi Assyaukani, "Islam dalam Konteks Pemikiran Pasca-Moderen: Pendekatan Menuju K ritik A kal Islam", dalam Jurnal Ulumul Q ur’an, no. 1, Vol. V 1994, 25.

35Jasser Auda, Maqasidal-Shar'ahasPhilosphyof IdamicSystemsA pproach(London-Washington: The International Institute of Islamic Thought, 2008), 26.

${ }^{36}$ Walaupun gagasan Jasser Auda berbicara dalam aspek hukum, tetapi teori sistem yang dia tawarkan juga dapat dipakai sebagai pisau analisis aspek-aspek Islam lainnya.

${ }^{37}$ Ibid., 45-55. 
of Isamiclaw); Sistem hukum Islam yang menyeluruh (whdeness of thesystem of Idamiclaw); Keterbukaan sistem hukum Islam (qpeness of thessstem of Isamic lan); Hirarki sistem hukum Islam (interndated hieardy of the system of Isamic lan); Multi-dimensi sistem hukum Islam (miltydimensionality of system of Idamiclaw); O ientasi tujuan sistem hukum Islam (purposfiulness of the system of Isamic lawi.

Pendekatan di atas dapat dilengkapi dengan tawaran metodologis Muhammad Shahrur dan secara meyakinkan dapat diterapkan dalam memahami teks-teks agama mengenai berbagai persoalan kontemporer, seperti persoalan pakaian.

\section{Pembacaan Kritis terhadap Teks}

D alam perspektif Islam, pakaian (libas) menempati posisi yang sangat signifikan terhadap pembentukaan pribadi muslim yang taqwa. Urgensi pakaian nampak, ketika Islam memerintahkan setiap individu baik laki-laki maupun perempuan agar menutupi aurat pada pelaksanaan ibadah, seperti sqlat, dan dalam pergaulan sehari-hari. ${ }^{38}$ Di samping sebagai penutup aurat, pakaian juga menjadi simbol karakter atau watak yang memakainya, ${ }^{39}$ bahkan oleh sebagian kalangan pakaian yang disinyalir sebagai pakaian islami, seperti hifab dan jilbab diyakini sebagai simbol keislaman yang menonjol. Lebih dari itu, hijabjuga menjadi simbol perlawanan terhadap hegemoni kebudayaan Barat yang oleh kalangan konservatif dianggap bertentangan denga ajaran Islam ${ }^{40}$.

Bagi Muhammad Shahrur ${ }^{41}$, salah seorang pemikir muslim kontemporer dari Syiria ini, hijab adalah pakaian untuk membedakan antara perempuan merdeka (al-hlmah) dan budak (al-'amah). Karenanya, tegas Shahrur, hijabbukanlah perintah Tuhan (taklif shar'ìyang bisa dihukumi halal-haram, tetapi ia tidak lebih dari sebuah tradisi pakaian sebelum islam (qabl b'that al-nabi)yang secara kebetulan berlaku pada masa Nabi Muhammad. Karenanya, lanjut Shahrur, pakaian hendaknya menyesuaikan dengan kebutuhan masyarakar dan lingkungan. ${ }^{42}$ Tokoh yang kelahiran D amaskus Syiria ini, memberikan pemikiran yang sangat kontroversial terhadap teks ayat-ayat libas (pakaian: hijab jilbabdan khimar), seperti penafsirannya berkaitan dengan surah al-Nur ayat 31:

"Katakanlah kepada wanita yang beriman: "Hendaklah mereka menahan pandangannya, dan kemaluannya, dan janganlah mereka menampakkan perhiasannya, kecuali yang (biasa) nampak dari padanya. D an hendaklah mereka menutupkan kain kudung ke dadanya, dan janganlah menampakkan perhiasannya kecuali kepada suami mereka, atau ayah mereka, atau ayah suami mereka, atau putera-putera mereka, atau putera-putera suami

${ }^{38}$ Periksa Abb al-Rahman al-Jazini, al-Fiqh'alaral-Madhabibal-Arba'ah, vol 2 (Istambul:Waqf al-Ikhlas, 1990), 191-192. ${ }^{39}$ Abdul Halim Syuqqah, KdədbasanWanita, vol 4, terj. As’ad Yasin (Jakarta: G ema Insani Press, 1997), 27.

${ }^{40}$ Periksa Nurul A gustin, SS, MA “G ender" Ensiklqpedi IsamTenatis vol 6 (Jakarta: Ihtiar Baru Van Hoeve, t.t), 182.

${ }^{41}$ Muhammad Shahrur dilahirkan di D amaskus, Suriyah pada tanggal 11 April 1938, putra dari perkawinan antara D eyb Shahrur dengan Siddiqah bin Słlih Filyun. Shahrur dikarunia lima orang anak:T ariq, al-Laith, Basul, Masun dan Rima sebagai buah pernikahannya dengan Azizah. Secara akademis dia meraih gelar D oktor di bidang Mekanika Pertanahan dan Fondasi (mikarikaturbat wa asasat) di Universits Irlandia. Kesibukannya sehari-hari adalah sebagai dosen Fakultas Teknik Sipil mengampu mata kuliah Mekanika Pertanahan dan Geologi. Hebatnya, dia produktif menulis tema-tema kajian keislaman dan menghasilkan karya monumental. Buku-buku yang telah dia terbitkan buah pikirannya antara lain: al-Kitabwaal-Qur'an: Qira'ahMua'asirah(D amaskus: al-A hali, 1990),

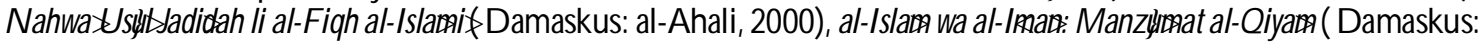
al- Ahali, 1994), DirasteIsamiyahMu'asirahfi al-Dawkhwaal-Mujtama' (D amaskus: al-Ahali, 1996).

${ }^{42}$ Muhammad Shahrur, NahwUsal, 355. 
mereka, atau saudara-saudara laki-laki mereka, atau putera-putera saudara lelaki mereka, atau putera-putera saudara perempuan mereka, atau wanita-wanita Islam, atau budak- budak yang mereka miliki, atau pelayan-pelayan laki-laki yang tidak mempunyai keinginan (terhadap wanita) atau anak-anak yang belum mengerti tentang aurat wanita. D an janganlah mereka memukulkan kakinyua agar diketahui perhiasan yang mereka sembunyikan. D an bertaubatlah kamu sekalian kepada Allah, hai orang-orang yang beriman supaya kamu beruntung".

Shahrur mengaskan, bahwa kata khumr dalam ayat di atas adalah berasal dari kata alkhamryang berarti penutup, sama saja penutup kepala, atau yang selainnya. Sedangkan kata juyb yang berarti sesuatu yang terbuka mempunyai dua tingkat, tidak sekedar satu. Lebih jauh, tokoh yang meraih gelar D oktor teknik sipil Universitas Irlandia ini menjelaskan, bahwa juyubbagi kaum perempuan adalah anggota tubuh antara dua belah dada (małaynal-thadyayn), bagian di bawah payudara (mataht) al-thadyayn), bagian di bawah ketiak (matablit al-ibtayn), kemaluan (al-faji), dan kedua bidang pantat (al-alyatayn). ${ }^{43}$

Perlu juga ditegaskan, bahwa Shahrur menggolongkan ayat 31 dari surah al-Nur di atas sebagai ayat hlıdud, sehingga ia menafsirkannya dengan pendekatan teori limit (nezgnijat al-hiludul) yang ia bangun. Batas minimal (al-hadd al-acha) bagian tubuh perempuan yang harus ditutupi adalah bagian-bagian yang termasuk kategori juybb dan batas maksimal (alhadd al-la) dan bagian-bagian mazhar minhał wajah, dua telapak tangan). ${ }^{44}$

Bias dari teori limit Shahrur di atas, bahwa perempuan yang menutup seluruh tubuhnya telah melanggar batas-batas (hildud) Allah, sebagaimana pelanggaran yang dilakukan oleh perempuan dengan memperlihatkan tubuhnya yang termasuk kategori juyub Menurut Shahrur, perempuan bebas berpakaian dengan mode apa saja selama tidak melanggar dua batas di atas, yakni batas ninimal dan batas maksimal. ${ }^{45}$

D alam mengkaji pakaian perempuan, Shahrur berpijak pada tiga landasan, yaitu: aspek metodologis, historis dan normatif. Berikut penulis kemukakan tiga landasan tersebut secara global.

\section{Landasan Metodologis}

Muhammad Shahrur, dalam bukunya, Naḩw Usłll Jadidah li al-Fiqh al-Isapi: Fiqh al-Mar'ah, meletakkan acuan metodologi yang dijadikan pijakan dalam memahami masalah pakaian (al-libas) ${ }^{46}$ perempuan yang dapat disimpulkan sebagai berikut. ${ }^{47}$

Petama, landasan kebahasaan (asaslughavi). Shahrur menolak terhadap sinonimitas

\footnotetext{
${ }^{43}$ Muhammad Shahrur, al-Kitab 607. Penafsiran Shahrur ini sangatlah "nakal" bila kita bandingkan dengan ulama' pendahulunya, seperti Ibn Jarir, al-Tabasari, al-Jassas, Ibn al-'Arabi. Periksa Ibn al-Jarir, Tafsir al-Tabari,yol 9 (Beirut: D azal-Kutub al-'Ilmiyah, 1992), 303, al-Tabarisi, Majma' al-Bayan vol 7 (Beirut: D asal-Fikr, t.t), 215-216, al-Jasłąs, Ahkamal-Qur'an, vol 3 (Beirut: D a sal-Fikr, t.t), 460-461, Ibn al-'Arabi, Ahkamal-Quran, vol 3 (Beirut: Dasal-Fikr, t.t),381-382.

${ }^{44}$ Ibid, 618.

${ }^{45}$ Ibid.

${ }^{46}$ Shahrur menggunakan istilah al-libas(pakaian) sebagai ganti istilah Hijabyang selama ini sering disebut pakaian shar' i`Berdasarkan penelitiannya, kata al-Hijabdalam al-Q ur'aß disebut 8 kali (dengan redaksi Hijab: al-A'raf 7: 46;

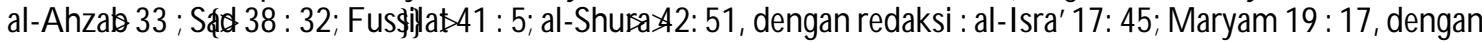
redaksi li mahjub: al-Mutaffifin 83: 15) tetapi setiap ayat tersebut tidak ada yang secara pasti dikaitkan dalam masalah pakaian. Kosa kata yang lebih merujuk pada pengertian al-libas menurut Shahrur, adalah al-thiyab(baju), al-jalakib(jilbab, penutup tubuh) dan al-khumr(kerudung). Periksa Shahrur, NahwaUsiliJadidah, 331.

${ }^{47}$ Ibid., 335.
} 
dalam kosa kata. Kata al-thawb (baju), dalam pengertian Shahrur tidak sama dengan kata al-libas (pakaian), kata al-sawah (kemaluan) tidak sama dengan kata al-'awrah Landasan linguistik ini menjadi pegangan Shahrur dalam membaca ayat-ayat al-Tanzilbal-Hakinł .

Keda, penyaringan arti kata secara tepat dan argumentatif (al-intiqais). Menurut Shahrur, terdapat sejumlah kata yang masing-masing mempunyai ragam makna, agar teks ayat al-Tanzil al-Hakimbeserta kandungan hukunnya dapat dipahami, harus diadakan seleksi secara ketat terhadap kosa kata tersebut ${ }^{49}$.

Ketiga, pembedaan antara halal (al-hollal) dan yang haram (al-horam), antara perintah (al-am) dan larangan (al-nahy), antara yang baik (al-hasan) dan yang buruk (al-cabiky). Penghollaban dan peng-hgraman adalah dua otoritas yang hanya dimiliki oleh Allah semata. O toritas untuk memberikan perintah dan larangan dimiliki oleh Allah serta para Nabi serta Rasul-Nya, karena dua otoritas tersebut mengandung unsur lokalitas dan tunduk pada kondisi darurat. D engan ungkapan lain bahwa kondisi darurat memperbolehkan hal-hal yang sebelumnya dilarang (al-manhiyat) bukan yang sebelumnya diharamkan (alminarramat). Sedangkan otoritas pembolehan (al-simah) dan pelarangan (al-man') dimiliki oleh Allah, para Nabi, para Rasul, dan pemimpin umat (uli øal-am). D alam hal ini yang termasuk ketegori uli sl-am, tegas Shahrur, adalah dewan legislatif, parlemen, dan dewan penasehat (ahl al-hill wa al-'aad). Adapun penetapan mana yang baik dan mana yang buruk (al-hasan va al-qabh) terletak di pundak setiap individu, baik secara perseorangan maupun kolektif dan yang diakui oleh hati nurani setiap manusia. Pemilihan hal-hal tersebut di atas merupakan dasar-dasar metodologi yang tidak pernah dikesampingkan oleh Shahrur ketika membca ayat-ayat al- Tanzibal-Hakim khususnya yang terkait denga ayat-ayat hukum. Berdasarkan pijakan ini, Shahrur menolak pendapat yang mangatakan bahwa para Rasul memiliki otoritas untuk menghalalkan dan mengharamkan sesuatu, kerena hal tersebut akan menghantarkan pada timbulnya kontradiksi dan pencampuradukkan pembaca ketika mengabaikan bahwa Rasul dan Nabi hanya menghlalkan dan mengharamkan sesuatu sebatas apa yang diwahyukan oleh Allah kepada mereka. Setiap Rasul ketika berijtihad, maka ijtihadnya berada dalam konteks kenabian (al-nubumwah), bukan dalam konteks kerisalahan (al-nisalah). Ijtihadnya bersifat lokal-temporal, memuat unsur perintah dan larangan, dan bukan penghalalan atau pengharaman. Para Rasul juga tidak menghalalkan atau mengharamkan sesuatu yang terpisah sama sekali dari prinsipprinsip Kitab Allah ${ }^{50}$

Keempat, desakralisasi terhadap tardisi (turath). Setiap yang berasal dari hasil karya cipta manusia dapat mengandung kesalahan, sekaligus kebenaran, kealpaan dan kelengahan, dan oleh karenanya dapat diperdebatkan serta dikaji ulang. ${ }^{51}$

\footnotetext{
${ }^{48}$ Ibid. menurut Shahrur, pemolakan sanonimitaslah yang pertama kali memberikan inspirasi untuk membedakan antar terma al-Kitab dan al-Q ur'an, antara al-Nabidan al-Rasul, antar al-Risalahdan al-Nubumuah yang kemudian menjadi embrio seluruh konsepnya yang kontroversial, baik di bidang 'ibadah, miamalahdan lainnya. Periksa

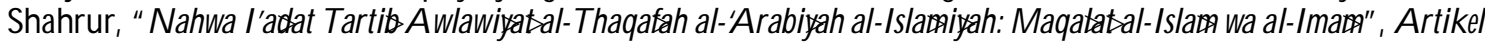
Studi Teks dan Tafsir(Yogyakarta: Hans Bunga, t.t), 2. Berkaitan dengan penolakan Shahrur terhadap sinonimitas bahasa, dia memilih kamus, Maqayis al-Lughah karya Ibn Faris. Kamus ini dijadikan rujukan utama untuk mendefinisikan perbedaan kata-kata yang dibahasnya. Periksa Shahrur, al-Kitab 24.

${ }^{49}$ Shahrur memberikan contoh perlunya penyaringan makna taquayang bersanding dengan kata libasdalam ayat 26 surah al-A'raf dalam tiga kemungkinan, yaitu: iman, amal saleh dan rasa malu. Periksa Sharur, NahmaUsłll,Ibid. 50Ibid.
} 
Keima, desakralisasi terhadap para pemegang otoritas tradisi. Sakralitas, menurut Shahrur, hanya berhak disandang oleh Allah dan Kitab-Nya, sedangkan imunitas dari kesalahan ('ismah) hanya dimiliki oleh Allah dan Rasul-Nya dalam lingkup-lingkup kerisalahan saja. Untuk alasan dan kepentingan apapun tidak diperbolehkan untuk menyandarkan imunitas tersebut kepada selain Allah dan Rasul-Nya, karena secara logika hal itu tidak dapat diterama. ${ }^{52}$

\section{Landasan Historis.}

Menurut Shahrur, masalah pakaian dan baju penutup bagi perempuan, adalah masalah klasik yang dapat dikembalikan kepada sejarah, bahkan pada masa pra-sejarah. Para pengkaji masalah ini senantiasa terikat dengan manuskrip-manuskrip klasik yang tidak dapat melepaskan diri dari persoalan-persoalan lain yang terkait, seperti masalah dosa pertama (al-khati'gh al-ula) yang selanjutnya terkait dengan masalah permulaan munculnya manusia, yaitu permulaan jenis manusia yang memiliki asal-usul fisik sebagai al-bashar sejak ruh ditiupkan dalam dirinya. Al-Tanzilbal-Hąkimsendiri mengindikasikan adanya hubungan tersebut dengan mengungkapkan bahwa usaha Adam dan pasangannya untuk menutupi bagian-bagian intim tubuhnya di surga merupakan hasil konstruksi alami ketika keduanya terbuka kemaluannya setelah memakan buah dari pohon terlarang. Hal ini, menurut Shahrur, sesuai dengan pendapat yang tedapat dalam tafsir-tafsir klasik ${ }^{53}$.

Menurut Shahrur, perempuan dalam masyarakat Arab sebelum diutusnya Muhammad dapat dikelompokkan ke dalam penganut agama Yahudi, Nasrani, dan penyembah berhala. Merekajuga tidak terlepas dari pengaruh minoritas penganut Ibrahim dan orang-orang Persia, khususnya terkait dengan hukum perdagangan. ${ }^{54}$

Secara geografis masyarakat pra-kenabian ini tersebar di daerah Hijaz dan seluruh bagian jazirah A rab. Sepanjang wilayah selatan mencakup daerah Yaman, wilayah daerah utara mencakup negeri Syam dan sebagian daerah Iraq. Mayoritas penduduknya hidup di daerah padang pasir dan wilayah tak bertuan yang diikat oleh silsilah keluarga dan suku. Sebagian kecil hidup di wilayah perkotaan yang berperan dalam menumbuhkan pasar dan aktifitas perdagangan secara menetap. Secara alamiah akan terdapat perbedaan secara konstruksi posisi perempuan dalam kedua wilayah yang berbeda tersebut. Secara alamiah, kontruksi pandangan tersebut turut membentuk pokok-pokok ajaran agama yang hidup saat itu. Yang jelas, para pengkaji masalah ini akan mendapatkan kenyataan bahwa perempuan Arab merdeka dalam masyarakat pra-kenabian memperoleh posisi yang tinggi dan terhormat sebagaimana kenyataan dalam adat, tradisi, kebisaaan, serta dalam berbagai bidang kehidupan, seperti pernikahan, penceraian, waris, hijab, pergaulan dengan lawan jenis, pembacaan puisi, dunia politik, hukum dan pertanian..$^{55}$

Berdasarkan fakta historisis, Shahrur menegaskan bahwa persoalan hijabdan jilbab adalah sarat dengan pengaruh tradisi bangsa-bangsa Mesopotamia, seperti Sumeria, Babilonia dan Assyiria. Di samping itu, ajaran agama-agama sebelum Islam, seperti

51'bid.

52Ibid.,337.

${ }^{53}$ Ibid.

54 Ibid.

${ }^{55}$ Ibid. 
Zoroaster, Manawiyyah, Yahudi dan Nasrani punya andil besar terhadap pola pikir beberapa kalangan yang diklaim sebagai "juru tafsir" al-Tanzilbal-Hakimdalam sakralisasi hijabdan jilbabdengan jargon "pakaian shariłat," dan -ironisnya diikuti oleh para pemikir islam berikutnya tanpa selektif. ${ }^{56}$

\section{Landasan Normatif}

Secara normatif, Muhammad Shahrur mendasarkan konsep pakaian "Islami" yang ia tawarkan pada dua ayat Hridudyang terdapat dalam Surah al-Nur ayat 30, tekait dengan laki-laki, dan ayat 31 terkait dengan perempuan.

Pada dasarnya, pemikiran Shahrur tentang pakaian berpijak pada dua ayat di atas yang kemudian yang didukung oleh ayat-ayat lainnya yang dianggap ada relevansi dengan tema pakaian. ${ }^{57} \mathrm{D}$ alam mengkaji tama-tema keislaman termasuk pakaian perempuan, Shahrur hanya bergantung pada al-Q ur'an, bukan Sunnah Nabi dan buku-buku lainnya. Sikap penolakan Shahrur terhadap sunnah, bukan berarti tidak menghargai Nabi, Shahrur menghargai Nabi dalam tingkah laku manusianya, sebagai seorang muslim pertama yang memilih pilihannya didalam batasan-batasan Tuhan. ${ }^{58}$

\section{Penutup}

Metodologi Studi Islam, sebagaimana disiplin ilmu pengetahuan lainnya, akan terus berkembang seiring dengan kebutuhan tantangan zaman yang bergulir begitu cepat. Bisa jadi, dalam hitungan beberapa tahun saja, bahkan mungkin bulan, Motodologi Studi Islam yang diusung oleh para pemikir, seperti dalam tulisan ini, sudah dianggap ketinggalan zaman. D an karenanya memerlukan inovasi-inovasi terbaru. Tentu sangat ironis, kalau Metodologi versi "lama" saja belum dipahami, apalagi mengaplikasikannya dalam sebuah penelitian, ternyata telah ditemukan Metodologi versi paling kontemporer.

Al-Hasil, siapapun yang tertarik dengan kajian ke-Islam-an, dituntut selalu mengupdate keilmuannya, serta berani menggunakan metode-metode kontemporer dalam menganalisis suatu permasalahan, sehingga menghasilkan sesuatu yang betul-betul baru (qira'ahmuntijah) dalam dunia ilmu pengetahuan, serta maskahahbagi planet bumi dan seisinya.

${ }^{56}$ Shahrur, NahwaUsklb,360. Sikap seperti itu menurut Shahrur, ada kesalahan fatal, karena merubah unirversalitas Islam menjadi pesan yang sempit, bersifat lokal, dan mengatributkan aspek kesakralan pada peninggalan tradisional, walaupun hal itu buah dari "rekayasa" interpretasi manusia, sehingga pesan yang orisinil menjadi tertutup oleh warisan manusia. Akibatnya kebudayaan Islam menjadi membatu. Periksa Muhammad Shahrur, TdksKetuhanan danPluralismepada MasyarakatMusim terj. Mohammad Zaki Husein (Yogyakarta: Hans Bunga, t.t), 44.

${ }^{57}$ Perlu dicatat, penyertaan ayat-ayat lain yang dimiliki topik pembahasan yang sama, dikenal dengan istilah metode intratekstualis, teknis dari metodis dari konsep al-Qur'anyufassir ba'dkhhba'd/sebagian ayat al-Q ur'an menafsirkan ayat lain). Ini sudah muncul sejak awal Islam, namun baru diaplikasikan secara sistematis pada abad ke-20, yang lebih popular dengan istilah al-tafsizal-mandj'słtafsir tematik). Perangkat metodologis ini memilki justifikasi dari Q.S, al-Muzammil: 4. Pada ayat tersebut terdapat kata tartilyang menurutnya tidak diartikan dengan membaca (tilawah) sebagaimana yang dipahami oleh sebagian mufassir. Lafaztersebut diambil dari kata al-ratl yang berarti "barisan pada urutan tertentu." A tas dasar ini, tartilvdiartikan dengan "mengambil ayat-ayat yang dikaitkan dengan satu topik dan mengurutkan sebagiannya di belakang yang lain". Periksa Shahrur, al-Kitab 197. Namun secara praktis, metode mandj'sini antara yang satu dengan yang lain terkadang terdapat perbedaan baik dalam hal memilih ayat maupun dalam hal analisis. Periksa Sahiron Syamsuddin, "Metode Intratekstualitas Muhammad Shahrur dalam Penafsiran al-Qur'an," Studi al-Qur'an Kontempare, ed. Abdul Mustaqim-Sahiron Syamsudin (Yogyakarta: PT Tiara Wacana Yogya, 2002), 138.

${ }^{58}$ Shahrur, Teks Keuhanan 49. 


\section{Daftar Rujukan}

Abdullah, Amin. "Mendengarkan "Kebenaran" Hermeneutika," dalam Fahruddin Faiz, Hemenatika Al-Qur an Yogyakarta: eLSAQ Press, 2005.

- - - - - . Isamic Studies di Pergunan Tingg. Yogyakarta: Pustaka Pelajar, 2006.

Aboe Fadl, K haled M. Atas Nama Tuhan: Dani Fikih Otoriter keFikih Otoritatif Tp: Serambi, 2004.

Abu Zaid, Nasr Hamid. Dava'ir al-Khant: Qira'ah fi Khitab al-Mar'ah Beirut: al-Markaz alThaqafi>al-'Arabi> 2000.

Adams, Charles J. "Islamic Religious Tradition", dalam Leonard Binder (ed.). TheStudyMide East: Reserch and Schdarship in Humanities and The Soial Saine Canada: John Wiley Sons, Inc, 1976.

Agustin, Nurul SS, MA. “Gender”Ensiklqped IslamTematis, Vol 6. Jakarta: Ihtiar Baru Van Hoeve, t.t.

Al-Jabiriy, Mohammad Abid. Takwin al-Ad al-'Arabi>Beirut: al-Markaz al-Thaqafi ‘l-'A rabi> 1991.

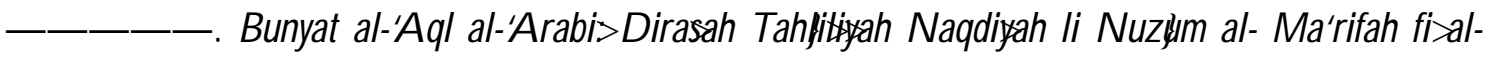
Thagafah al-Arabiyah Beirut: Markaz D irasat al-Wihdlah al-'A rabiyah, 1990.

al-Jaziri, Abd al-Rahman. al-Fiqh ‘alazl-Madhakibal-Arba'ah, vol 2. Istambul: Waqf al-Ikhlas,\} 1990.

al-Shatibi, Abu Ishaq. al-MumafaqatefiUsjlabal-Shan'gh vol 2. Beirut: D as al-Kutub al-'Ilmiłah, 1971.

Arabi, Ibn al. Ahkamal-Quran, vol 3. Beirut: Das al-Fikr, t.t.

Arkoun, Muhammad. Al-Fikr al-Usjlitiva Istijhalateal-Tásil', terj. Hashim Salih. Beirut: D as alSaøi> 1999.

- - - - - . RehinkingIsam terj. Yudian W. Asmin \& Lathiful K huluq. Yogyakarta: Pustaka Pelajar, 1996.

Assyaukani, Luthfi. "Islam dalam Konteks Pemikiran Pasca-Moderen: Pendekatan Menuju

Kritik Akal Islam", dalam Jumal Ulumi Quran no. 1, Vol. V 1994.

Auda, Jasser. Maqaid al-Shar'’h As Philospdy of Islamic Systens Approadh London-Washington: The International Institute of Islamic Thought, 2008.

Bertens, K. Filsafat Barat Abad XX: InggisJeman Jakarta: G ramedia, 1983.

Erricker, Clive. "Pendekatan Fenomenologis," dalam Peter Conolly (ed). Anka Pendkkatan

Studi Aggma, terj. Imam Khoiri. Yogyakarta: PT. LKiS Printing Cemerlang, 2009.

Fanani, Muhyar. Metode Studi Islam Aplikasi Sosidog Pengtahuan sebagai Cara Pandang Yogyakarta: Pustaka Pelajar, 2008.

Hardiman, F. Budi. "Positivisme dan Hermeneutik: Suatu Usaha untuk "Subjek", dalam Basis XL-3 (Maret 1991).

Hardiman, F. Budi. Kritik Idedog:: Menjingkap Kepertingan Pengtahuan Besama Jurgen Habemas Yogyakarta: Buku Baik, 2004.

Jarir, Ibn al. Tafsizal-Tábani>vol 9. Beirut: Dał al-Kutub al-'Ilmiłah, 1992.

Jassas, al. Ahkamal-Quran, vol 3. Beirut: D as al-Fikr, t.t.

K. Munitz, Milton. Contemparary Analytic Philosqphy. London: Collier Macmillan Publishers, 1981. 
L. Cox, A, A. James. Guide to thePhenomendogy of Rdegin: Key Figures, Fomative Influnces and Subsequent Debates New York: The Open University, 2006.

Mas'ud, Abdurahman. "Sunnisme and 'Orthodox' in Eyes of Modern Scholars." Al-Jam'ah Jaumal of IsamicStudes no. 61 (1998). Sheila Mc D onough, "O rthodoxy and Heterodoxy, dalam, Enoydqpedia of Reigion vol. 11, 108, 124.

Maulidin. "Sketsa Hermeneutika" dalam Gedbang Jumal Studi Agama dan Demokrasi, no.14 Vol.V. Surabaya: Lembaga Studi Agama dan D emokrasi, 2003.

Nugroho, Heru. Menumbuhkan Ideide Kritis Yogyakarta: Pustaka Pelajar, 2003.

Rumadi. "Kritik Wcana Agama sebagai G erakan Pemikiran Islam Kontemporer," dalam ed. Adnan Mahmud, et.al. Pemikiran Isam Kontemparer di Indonesia. Yogyakarta: Pustaka Pelajar, 2005.

Saed, Abdullah. Interpretingal-Quran: Towards a ContempararyApproadh N ew York: Routledge, 2006.

Sahiron, Abdul Mustaqim. Syamsudin. Yogyakarta: PT Tiara Wacana Yogya, 2002.

Sahrodi, Jamali. Metoddog Stud Isam Mendusur Jgjak Hisoris KajïanIsamala Sajana Orientalis Bandung: Pustaka Setia, 2008.

Schwartz, Stepen Sulaiman. Dua Wajah Isam Modaratisme vs. Fundametalisme dalam Wacama Gldbal. Jakarta: The Wahid Institute, 2007.

Sharur, Muhammad. al-Isamwa al-Iran: Manzjmat al-Qiyarn D amaskus: al- Ahali, 1994.

- - - - - .al-Kitab wa al-Qư'art Qira'ah Múasirah D amaskus: al-A hali, 1990.

- - - - . Nahna \Uskil Jadidah li al-Fiqh al-Isami>D amaskus: al-A hali, 2000.

- - - - - Dirasat Isamiyah Múasirah fi al-Dawah na al-Mijtamá. D amaskus : al-Ahali, 1996.

Syuqqah, A bdul Halim Kdðbasan Wanita, Vol 4, ter As'ad Yasin. Jakarta: Gema Insani Press, 1997.

Tabarisi, al. Majma al-Bayan, vol. Beirut : D ar al-Fikr, t.t.

van Ess, Josef "The Logical Structure of Islamic Theology," dalam Issa J. Boullata (ed.), An Anthdogy of Isamic Studies Montreal, MoGill Indonesia IAIN D evelopment Project, 1992. 